\title{
Comprehensive Control of Proton Exchange Membrane Fuel Cell as Backup Power Supply for UPS
}

\author{
Yuedong Zhan ${ }^{1}$, Youguang Guo ${ }^{2}$, Jianguo Zhu², Hua Wang ${ }^{1}$ \\ 1. Kunming University of Science and Technology, Kunming 650051, China \\ E-mail: yuedong@eng.uts.edu.au \\ 2. Faculty of Engineering, University of Technology, Sydney, PO Box 123, Broadway, NSW 2007, Australia \\ E-mails: youguang@eng.uts.edu.au, joe@eng.uts.edu.au
}

\begin{abstract}
To improve the performance of a proton exchange membrane fuel cell (PEMFC) stack, it is important to avoid the hydrogen and oxygen/air starvation of electrochemical reaction, prevent the dehydration and drying of the membrane, and track the output power. This paper conducts research in a comprehensive control strategy of the operation parameters of an uninterruptible power system (UPS) with backup PEMFC and battery power sources, such as the thermal management and control of operating temperature, pressures and mass flows of hydrogen and air for the PEMFC stack, switch of the power supply between PEMFC and battery for UPS, and the output power tracking of PEMFC. Based on the dynamic model of the anode and cathode flow system, the models of manifold and the performance curve, a detail model analysis is presented. A comprehensive control method is proposed and applied to the PEMFC system employed for the power source of UPS. The experimental results show that the comprehensive control method can effectively keep constant pressures of the inlet hydrogen and air, automatically switch the power supply between PEMFC and battery, reasonably improve the performance of the PEMFC through thermal management and control of operating temperature, and track the real-time changes of the output power and the distribution of the mass flows of hydrogen and oxygen/air.
\end{abstract}

Key Words: Proton exchange membrane fuel cell, Backup power supply, Uninterruptible power system (UPS), Dynamic model; Comprehensive control

\section{INTRODUCTION}

To supply high quality power to critical loads such as computers and communication equipments, an uninterruptible power system (UPS) with clean output voltage with low total harmonic distortion (THD) for both linear and nonlinear loads, high efficiency, great reliability and fast transient response for sudden power grid failure and load changes, is desired. Due to the high electrical efficiency, flexibility with respect to power and capacity, long lifetime and no pollution, the fuel cells, including the proton exchange membrane fuel cell (PEMFC), are rapidly becoming a significant power source in the design and development of UPS [1]. Because the PEMFC converts the chemical energy of hydrogen and oxygen directly and efficiently into electrical energy, its main characteristics include: producing water in the cathodes as a byproduct, which does not pollute the environment; having higher efficiency and power density when compared with the heat engines; operating at low temperatures (less than $100{ }^{\circ} \mathrm{C}$ ), which allows a fast start-up; using a solid polymer as the electrolyte, which reduces the concerns on construction, transportation and safety [2].

In the last decade, the performance of fuel cells has been greatly improved mainly due to the advances of PEMFC, and a large amount of work was conducted by various researchers for predicting the performance, which is a key factor in the development of new applications. For application of PEMFC in UPS as the backup power source, a dynamic model for efficiently predicting the system performance is important, especially when the operation conditions vary. The power response of the PEMFC system depends mainly on the interaction of the PEMFC stack and its peripheral components like hydrogen and air supply, mass flow and pressure control, heat and water management. To provide sufficient power to the external load, the UPS system employing a PEMFC as the main power source adopts a battery or supercapacitor to prevent the PEMFC from excessive use and fuel/gas starvation, and to feed power smoothly to the external load. Hence, the control objectives for a UPS with backup power supply are to maintain efficiency and to avoid degradation by guaranteeing appropriate temperature, flows and partial pressures of the reactants across the electrode [3].

In this paper, based on analyzing the dynamic model of the PEMFC, including the dynamic gas transport model, the manifold model and the performance curve model in details in Section 2, investigates a comprehensive control of operational parameters of the PEMFC stack in Section 3, such as the stack temperature, the pressures and mass flows of the hydrogen and air, the power tracking of load for PEMFC or UPS, and the power supply switching between PEMFC stack and battery. Section 4 presents the experimental results, showing that with the proposed control on the PEMFC stack parameters, heat and water management, not only has the performance of PEMFC been improved, but also the operating stability of PEMFC has been enhanced.

As the example, a single-phase high frequency 500W UPS with PEMFC/battery hybrid power source is introduced. Fig. 1 illustrates schematically the structure of the UPS with a backup PEMFC generating system and battery, which 
consists of DC/AC inverter, DC/DC converter, AC/DC rectifier, and $\mathrm{AC} / \mathrm{DC}$ charger, and their data-acquisition and control units. The UPS supplies the linear and nonlinear loads with the required uninterruptible AC power. The PEMFC stack operates on hydrogen and air. Because of the slow start-up of the PEMFC stack, which may take a few seconds, a small capacity battery is required for UPS applications. The UPS system designed has a lot of advantages: low cost, weight, size and so on.

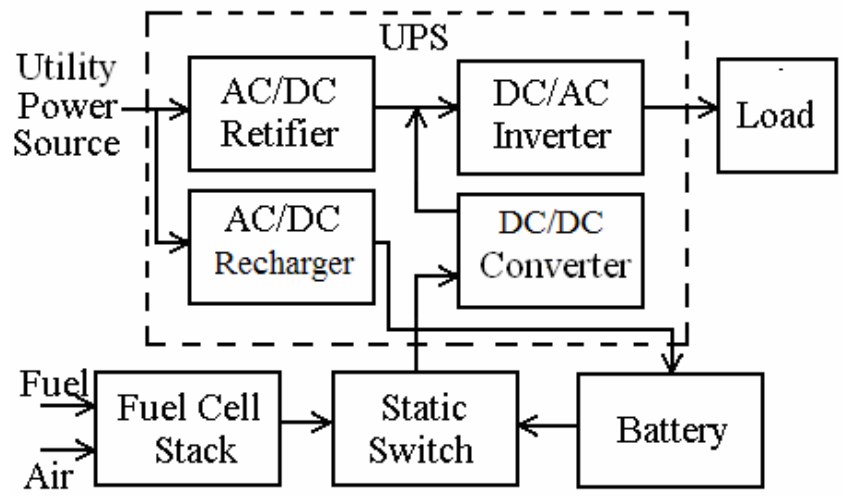

Fig. 1: Single-phase UPS with backup PEMFC and battery

\section{DYNAMIC MODEL ANALYSIS OF PEMFC}

\subsection{Dynamic Gas Transport Model}

According to the conservation of energy and the ideal gas law, the partial pressure of each gas is proportional to the amount of the gas in the stack, which depends on the gas inlet flow rate, gas consumption and gas outlet flow rate [4]. Thus, the state equations become:

$$
\begin{aligned}
& \frac{d P_{H_{2}}}{d t}=\frac{R T}{V_{a n}}\left(Q_{H_{2}}^{\text {in }}-Q_{H_{2}}^{\text {out }}-Q_{H_{2}}^{r c t}\right) \\
& \frac{d P_{\mathrm{O}_{2}}}{d t}=\frac{R T}{V_{c n}}\left(Q_{\mathrm{O}_{2}}^{\text {in }}-Q_{\mathrm{O}_{2}}^{\text {out }}-Q_{\mathrm{O}_{2}}^{\text {rct }}\right) \\
& \frac{d P_{\mathrm{H}_{2} \mathrm{O}}}{d t}=\frac{R T}{V_{c n}}\left(Q_{\mathrm{H}_{2} \mathrm{O}}^{\text {in }}-Q_{\mathrm{H}_{2} \mathrm{O}}^{\text {out }}+Q_{\mathrm{H}_{2} \mathrm{O}}^{\text {produced }}\right)
\end{aligned}
$$

where $P_{j}\left(j=H_{2}, \mathrm{O}_{2}, \mathrm{H}_{2} \mathrm{O}\right)$ is the partial pressure of each gas (atm); $Q^{i n}$ the inlet flow rate of hydrogen, oxygen, and the water of the cathode $(\mathrm{kmol} / \mathrm{s}) ; Q^{\text {out }}{ }_{j}$ the outlet flow rate of each gas (kmol/s); $Q^{r c t}{ }_{j}$ the electrochemical reactions, $Q^{\text {produced }}{ }_{\mathrm{H} 2 \mathrm{O}}$ the production of water (kmol/s); $R$ the universal gas constant (atm/kmol K); $T$ the absolute temperature $(\mathrm{K})$; $V_{a n}$ the anode volume (l); and $V_{c n}$ the cathode volume (l).

The proportional relationship between the gas outlet flow through a valve and the partial pressure can be calculated as

$$
\begin{aligned}
& \frac{Q_{H_{2}}^{\text {out }}}{P_{H_{2}}}=\frac{k_{a n}}{\sqrt{M_{H_{2}}}}=k_{H_{2}} \\
& \frac{Q_{O_{2}}^{\text {out }}}{P_{\mathrm{O}_{2}}}=\frac{k_{c n}}{\sqrt{M_{O_{2}}}}=k_{O_{2}}
\end{aligned}
$$

$\frac{Q_{\mathrm{H}_{2} \mathrm{O}}^{\text {out }}}{P_{\mathrm{H}_{2} \mathrm{O}}}=\frac{k_{c n}}{\sqrt{M_{\mathrm{H}_{2} \mathrm{O}}}}=k_{\mathrm{H}_{2} \mathrm{O}}$

where $k_{j}\left(j=H_{2}, \mathrm{O}_{2}, \mathrm{H}_{2} \mathrm{O}\right)$ is the valve molar constant of each gas $(\mathrm{kmol} / \mathrm{atm} / \mathrm{s}) ; k_{a n}$ and $k_{c n}$ are the anode and cathode valve constants $(\sqrt{\mathrm{kmol} \bullet \mathrm{kg}} / \mathrm{atm} / \mathrm{s})$; and $M_{j}$ is the molar mass of each gas $(\mathrm{kg} / \mathrm{kmol})$.

In the electrochemical reaction, the amount of each gas can be described as

$$
\begin{aligned}
& Q_{H_{2}}^{r c t}=\frac{N_{C E L L} I}{2 F}=2 k_{r} I \\
& Q_{\mathrm{O}_{2}}^{r c t}=\frac{N_{C E L L} I}{4 F}=k_{r} I \\
& Q_{\mathrm{H}_{2} \mathrm{O}}^{\text {produced }}=\frac{N_{C E L L} I}{2 F}=2 k_{r} I
\end{aligned}
$$

where $N_{C E L L}$ is the number of the series-connected fuel cells in the stack; I the stack current (A); $F$ the Faraday's constant $(\mathrm{C} / \mathrm{kmol})$; and $k_{r}$ the modeling constant ( $\left.\mathrm{kmol} / \mathrm{s} / \mathrm{A}\right)$.

When the Laplace transform is applied to (1)-(3), whose parameters are input to (4)-(9), and considering $Q^{i n}{ }_{\mathrm{H}_{2} \mathrm{O}}=0$, the partial pressure of each gas can be rewritten in the $S$ domain as

$$
\begin{aligned}
& P_{\mathrm{H}_{2}}=\frac{1 / k_{\mathrm{H}_{2}}}{1+\tau_{\mathrm{H}_{2}} \mathrm{~S}}\left(Q_{\mathrm{H}_{2}}^{\text {in }}-2 k_{r} I\right) \\
& P_{\mathrm{O}_{2}}=\frac{1 / k_{\mathrm{O}_{2}}}{1+\tau_{\mathrm{O}_{2}} \mathrm{~S}}\left(Q_{\mathrm{O}_{2}}^{i n}-k_{r} I\right) \\
& P_{\mathrm{H}_{2} \mathrm{O}}=\frac{1 / k_{\mathrm{H}_{2} \mathrm{O}}}{1+\tau_{\mathrm{H}_{2} \mathrm{O}} \mathrm{S}}\left(Q_{\mathrm{H}_{2} \mathrm{O}}^{\text {in }}+2 k_{r} I\right)=\frac{1 / k_{\mathrm{H}_{2} \mathrm{O}}}{1+\tau_{\mathrm{H}_{2} \mathrm{O}}}\left(2 k_{r} I\right)
\end{aligned}
$$

where $\tau_{\mathrm{H}^{2}}=V_{a n} /\left(k_{\mathrm{H} 2} R T\right)$ and $\tau_{\mathrm{O}_{2}}=V_{c n} /\left(k_{\mathrm{O} 2} R T\right)$ are the time constants of the gases (s).

\subsection{Manifold Model}

Eq. (10) describes the relationship between the stack current and hydrogen partial pressure, and (11) the relationship between the stack current and oxygen partial pressure. Considering that it is difficult to measure the partial pressure of the gases, but the inlet manifold or a pipe pressure of hydrogen and oxygen can be measured, the lumped pneumatic model is achieved by developing an equivalent circuit diagram using a pneumatic resistance and a capacity of the pneumatic system, as shown in Fig. 2 [3].

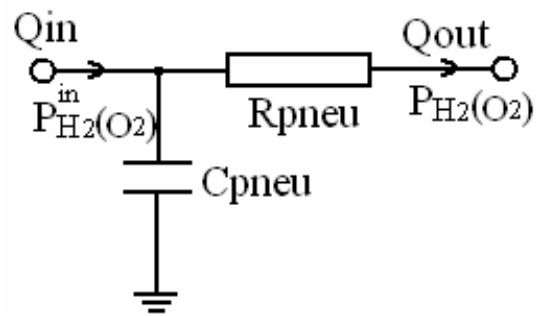

Fig. 2: Manifold model 
The dynamics of the pneumatic system can be described by a set of first-order differential equations as

$Q_{H_{2}}^{\text {in }}=C_{H_{2} \text { pпеи }} \frac{d P_{H_{2}}^{\text {in }}}{d t}+\frac{P_{H_{2}}^{\text {in }}-P_{H_{2}}}{R_{H_{2} \text { рпеи }}}$

$Q_{O_{2}}^{\text {in }}=C_{O_{2} \text { pneu }} \frac{d P_{O_{2}}^{\text {in }}}{d t}+\frac{P_{O_{2}}^{\text {in }}-P_{O_{2}}}{R_{O_{2} \text { pnеu }}}$

By applying the Laplace transform to (13) and (14), the inlet gas pressure can be calculated as

$P_{H_{2}}^{\text {in }}=\frac{1}{1+\tau_{\mathrm{H}_{2} \text { pneu }}}\left(R_{\mathrm{H}_{2} \text { pneu }} Q_{\mathrm{H}_{2}}^{\text {in }}+P_{\mathrm{H}_{2}}\right)$

$P_{\mathrm{O}_{2}}^{\text {in }}=\frac{1}{1+\tau_{\mathrm{O}_{2} \text { pпеи }}}\left(R_{\mathrm{O}_{2} \text { рпеи }} Q_{\mathrm{O}_{2}}^{\text {in }}+P_{\mathrm{O}_{2}}\right)$

where $P_{\mathrm{H}_{2}}^{i n}$ and $P^{i n} \mathrm{O}_{2}$ are the inlet pressure of the hydrogen and oxygen manifold (atm); $R_{\text {Нгрnеи }}$ and $R_{\text {Огрпеи }}$ the

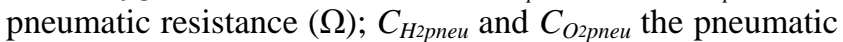
capacitance $(\mathrm{F})$; and $\tau_{\mathrm{H}_{2 p n e u}}$ and $\tau_{\mathrm{O} \text { рпеи }}$ the pneumatic time constant of the hydrogen and oxygen manifold (s), respectively.

\subsection{Polarization Curve Model}

The PEMFC stack terminal voltage, $V_{\text {stack }}$, is determined by subtracting various voltage losses from the reversible voltage as

$V_{\text {stack }}=V_{\text {reversible }}-V_{\text {actLOSS }}-V_{\text {ohmLOSS }}-V_{\text {conLOSS }}-V_{\text {leakLOSS }}$

where $V_{\text {reversible }}, V_{\text {actLoss }}, V_{\text {ohmLoss }}, V_{\text {conLoss }}$ and $V_{\text {leakLoss }}$ are the maximum theoretical voltage or reversible voltage, activation voltage loss, ohmic voltage loss, concentration voltage loss and leakage loss, respectively.

These voltage losses result in an operating voltage below the reversible voltage as shown in the typical polarization curve in Fig. 3. It shows that there are different losses at different current densities. These losses, which are called the irreversible losses, are associated with the internal structures of the fuel cells, the external operating conditions, and fuel cell controlling strategies. Four primary irreversible losses that result in the degradation of fuel cell performance are the activation polarization loss, ohmic loss, concentration polarization loss and leakage loss, and their models can be found in $[5,6]$.

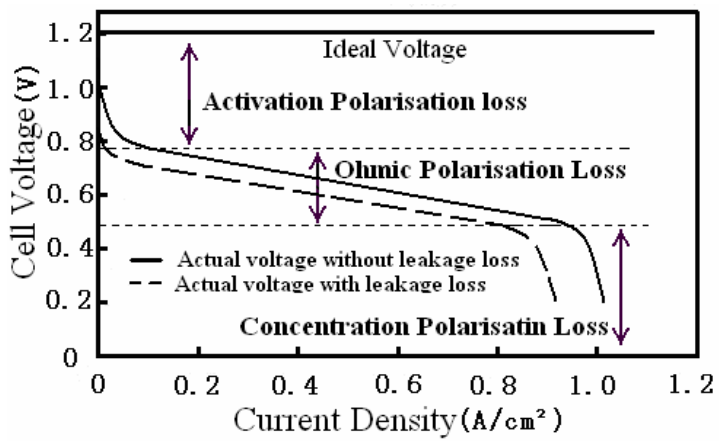

Fig. 3: Ideal and actual performance curves of a PEMFC

\subsection{Detailed Model of PEMFC}

According to the above analysis, a detailed PEMFC model is developed as shown in Fig. 4. The model is based on the relationship between the output voltage and the partial pressures of gases, temperature of the stack and water.

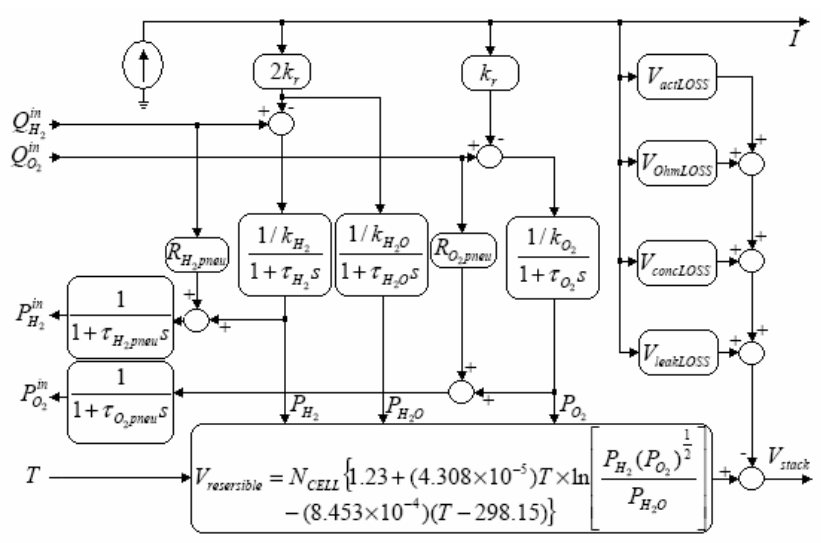

Fig. 4: PEMFC model

\section{COMPREHENSIVE CONTROL DESIGN}

Fig. 5 illustrates the block diagram of the PEMFC power system for UPS, which consists of a self-humidification stack and four control subsystems: the hydrogen mass flow control (HMFC), the oxygen/air mass flow control (OMFC), the water and thermal management, and the power tracking control. In the figure, $\mathrm{M}$ is a multiplier for calculating the output power of the PEMFC; $\mathrm{D}$ is a fast recovery diode; and $\mathrm{SCR}_{1}$ is a silicon-controlled rectifier for switching the power source between PEMFC and battery for UPS when the load increases sharply or the utility grid power fails.

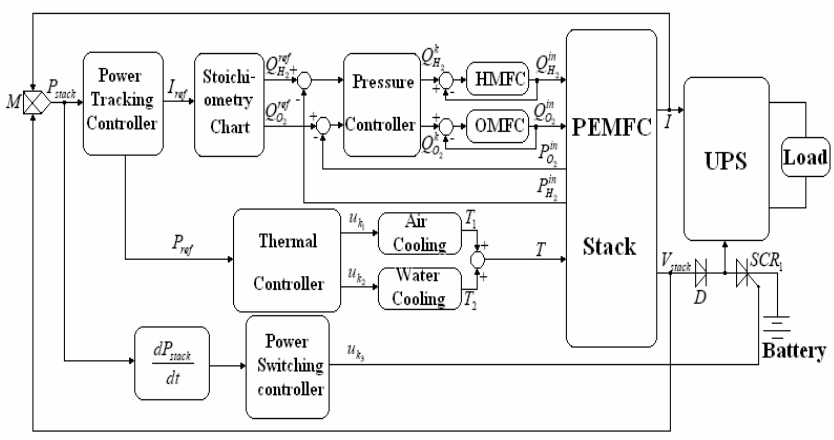

Fig. 5: Schematic diagram of the PEMFC power system for UPS

\subsection{Power Tracking Controller}

A double closed-loop (current and voltage) control system has been developed for the PEMFC. According to the real-time current and voltage values of PEMFC, the power density (ranging from 12 to $500 \mathrm{~W}$ ) can be firstly calculated. Based on the load at that time, a power tracking controller is designed to continuously distribute the current or real time power by using the setup value of the reference mass flow $Q^{r e f}{ }_{H_{22}}$ and $Q^{r e f}{ }_{\mathrm{O} 22}$ of hydrogen and oxygen/air and according to the stoichiometry chart of PEMFC. The stoichiometry chart for hydrogen and air flows for a self-humidified PEMFC stack is shown in the Table 1 [7]. If the load is over $500 \mathrm{~W}$, the controller will shut down the PEMFC generating system. 
Tab. 1: Stoichiometry Chart for Air and Hydrogen Flows

\begin{tabular}{l|l|l|l|l}
\hline \hline \multirow{2}{*}{$\begin{array}{c}\text { Current } \\
(\mathrm{A})\end{array}$} & \multicolumn{2}{|c|}{ Air flow (SL/min) } & \multicolumn{2}{c}{$\mathrm{H}_{2}$ flow (SL/min) } \\
\cline { 2 - 5 } & Sto.=2.0 & Sto.=2.5 & Sto.=1.0 & Sto.=1.2 \\
\hline 5 & 5.6 & 7.0 & 1.1 & 1.3 \\
\hline 10 & 11.2 & 13.9 & 2.2 & 2.7 \\
\hline 15 & 16.7 & 20.9 & 3.3 & 4.0 \\
\hline 20 & 22.3 & 27.8 & 4.5 & 5.3 \\
\hline 25 & 27.8 & 34.8 & 5.6 & 6.7 \\
\hline 30 & 33.4 & 42.1 & 6.7 & 8.0 \\
\hline \hline
\end{tabular}

\subsection{Thermal Controller}

The PEMFC belongs to the low temperature stack $\left(<100^{\circ} \mathrm{C}\right)$ in the fuel cell family, but its operating temperature is still higher than the ambient temperature and should be maintained within an appropriate range. The operating temperature is selected according to the characteristics of the PEMFC offered by the manufacture. For the PEMFC studied in this paper, the best operating temperature is within $60 \sim 65^{\circ} \mathrm{C}$.

Two kinds of cooling method are used: air cooling and water cooling. Under the low current and power $(<200 \mathrm{~W})$, it is possible to use the air cooling to obtain a satisfactory result. However, when operating in high current and power, the stack should adopt the water cooling. The heat management system of PEMFC will be given in the next section. The experiment proves that it is necessary to have an effective heat dissipation to prevent the fuel cell from high temperature and the proton exchange membrane from dehydration.

The thermal control rules are: (1) If power is less $200 \mathrm{~W}$ and temperature is less than $60^{\circ} \mathrm{C}$, air cooling is used; (2) If power is over $200 \mathrm{~W}$ and temperature is less than $65^{\circ} \mathrm{C}$, both air cooling and water cooling are used; (3) If power is over $500 \mathrm{~W}$ or temperature is over $65^{\circ} \mathrm{C}$, the PEMFC is shut down.

\subsection{Fuzzy Logic Controller of Mass Flows of Hydrogen and Air}

The fuzzy-PI controller input variable are the mass flow error $e(k)$, and the change of error $c(k)$ of hydrogen or air. The output variables of the controller are the optimal $P$ and $I$ gains of a subsequent PI controller device, one of them gives the proportional part $K$ as a function of $e(k)$ and $c(k)$, and the other gives the increment $\Delta T$, which is then integrated to provide the integral term $T$ of the PI controller. There are the seven fuzzy subsets: positive big (PB), positive medium (PM), positive small (PS), zero (ZE), negative small (NS), negative medium (NM), and negative big (NB), have been selected for the input and output variables $e(k), c(k), K$ and $T$. The fuzzy control rules are obtained from the behaviour analysis of the PEMFC system. Because the rule-base represents the intelligence of the controller, the formulations must be carefully considered. Correct use of control laws according to the operating conditions can greatly improve the system stability. A fast response with a small overshoot for the PEMFC system can be achieved with proper handling of the proportional and integral part. As shown in [8], the fuzzy-PI controller is more advantageous than a standard PI controller.

\subsection{Pressure Controller}

An increase in PEMFC operating pressure results in higher cell voltage according to the Nernst equation and the increase in exchange current density due to increased concentration of reactant gases in the PEMFC electrodes. According to the demands of the PEMFC, this paper adopts the steady pressure equipment to control the reactant gas pressure. The system can also control the hydrogen pressure at about $34.5 \mathrm{kPa}$ (5 psi). An air compressor is used to feed air. After the gas pressure reaches the predetermined value, the air quantity in the air compressor should be controlled according to the rate of utilizable air and the working current of the stack decided by the experiment. The air pressure value is adjusted to around $68.9 \mathrm{kPa}(10 \mathrm{psi})$.

\subsection{Power Switch Controller}

The complex electrode phenomenon existing in the PEMFC is caused by the double charge layer. This acts as a capacitance and gives the fuel cell stack a smooth dynamic voltage output. When the load of the fuel cell stack changes, the voltage output has an initial Ohmic voltage loss due to the resistance of the fuel cell stack and then it slowly moves to a new voltage [9]. When the load is suddenly increased, the HMFC and OMFC may not be able to provide sufficient hydrogen and air to sustain the operation under the new load condition. This can lead to temporary hydrogen and air starvation, thereby causing irreversible damage of the PEMFC stack. To avoid this, in this paper a power switch controller is designed, which can control the power source of UPS to switch from PEMFC to battery according to the change rate of the power of the PEMFC stack. Transient issues associated with temporary hydrogen and air starvation can be avoided by supplying the power from the battery and slowing down the current drawn from the PEMFC through a change rate limiter of the output power.

\section{EXPERIMENTAL RESULTS}

Experimental study has been conducted on the designed UPS with backup PEMFC and battery. The proposed comprehensive control strategies have been implemented in the PEMFC test system available in the University of Technology Sydney (UTS) fuel cell laboratory. Based on the comprehensive control, the output voltage and current values of the PEMFC stack are controlled according to the load changes of the UPS, as shown in Fig. 6.

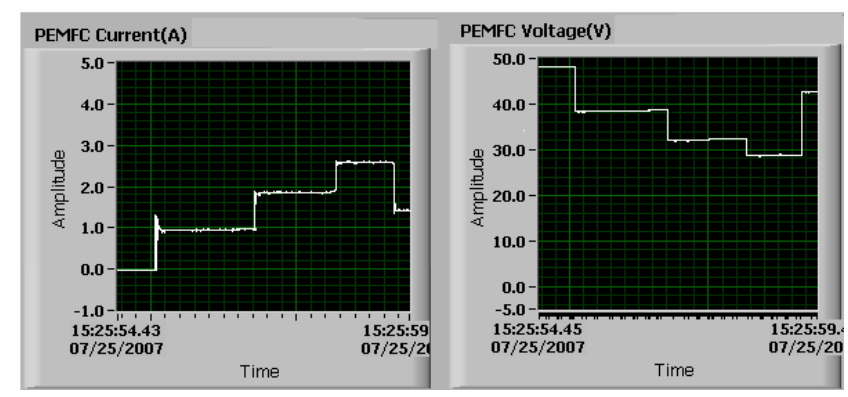

Fig. 6: Current and voltage of PEMFC when the UPS load changes

The experimental results reveal that when the external load has a sudden change, the hydrogen cannot be fed fast enough to the PEMFC stack. When the load of the UPS 
suddenly changes, for example, from $60 \mathrm{~W}$ to $120 \mathrm{~W}$, the output voltage of the PEMFC stack goes down quickly and makes the UPS shut down, resulting in hydrogen and air starvation and damage of the PEMFC stack. To supply enough power to the external load and protect the PEMFC stack, the UPS system should keep the lead-acid battery. As shown in Fig. 7, the PEMFC stack can supply the UPS with power source for a long time in the normal conditions, and when the load sharply changes, the power switch controller can switch on the battery, which can supply the UPS in parallel. The experiment shows that the load rise can keep the current from the battery higher than that from the PEMFC over time.

With the increase of the load, the temperature of PEMFC stack will go up. With the thermal controller, the temperature of the stack can be kept in the range of 60 65 ${ }^{\circ} \mathrm{C}$, as shown in Fig. 8. The comprehensive control performance curve and the conventional PI control performance of PEMFC stack are given in Fig. 9. In general, higher operating temperature is desirable due to decreased mass transport limitations and increased electrochemical reaction rates; at the same time, high temperatures may lead to increased mass transport losses due to the increases in water vapor.

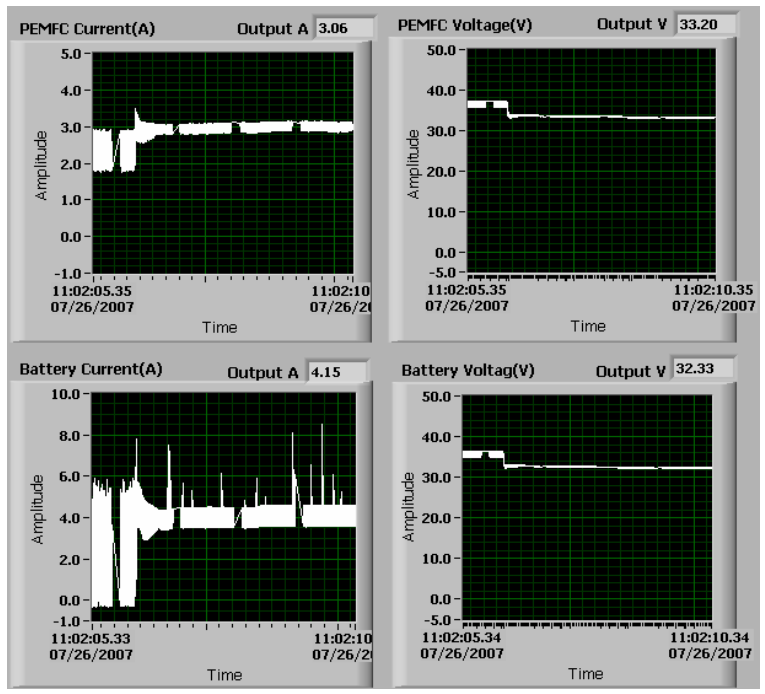

Fig. 7: Current and voltage of the PEMFC and battery when the load of UPS changes from $60 \mathrm{~W}$ to $210 \mathrm{~W}$

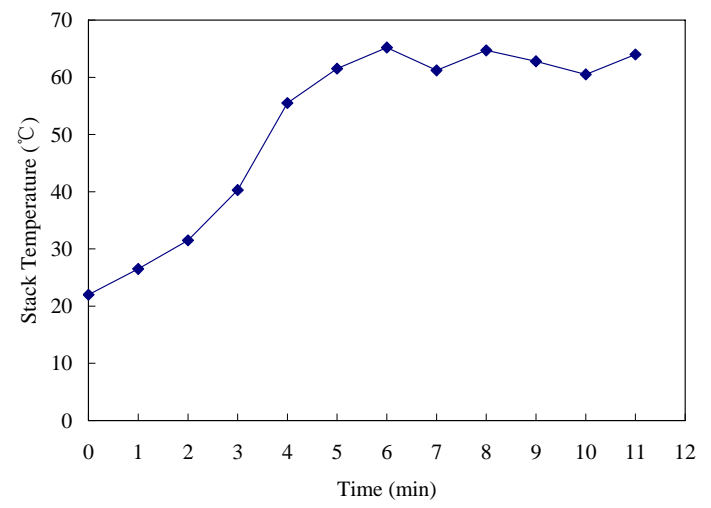

Fig. 8: Stack Temperature

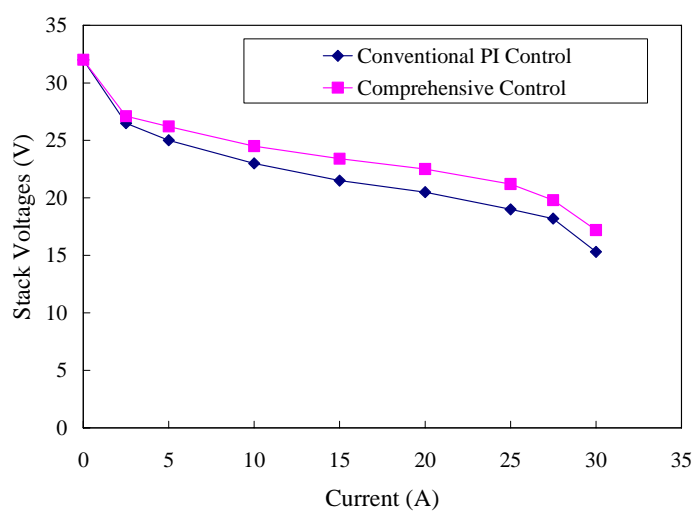

Fig. 9: Comparison of performance between comprehensive control and conventional PI control

\section{CONCLUSION}

This paper presents a comprehensive control method for improving the PEMFC performance at different operational conditions. For avoiding the hydrogen and air starvation and flooding of PEMFC stack, and tracking the output power of PEMFC, a comprehensive controller has been designed to control the input mass flows and pressures of hydrogen and air, the stack temperature and the switching of the power sources between the PEMFC stack and battery. The experimental results have proved that the proposed comprehensive control scheme can work better than the conventional control strategy.

\section{REFERENCES}

[1] J. B. Jia, Y. T. Cham, Y. Wang, F. Lewis. The electrical dynamic response study of PEMFC as a backup power supply, Proceedings of IEEE International Conference on Control and Automation[C], Guangzhou, China, 2007: 1156-1161.

[2] G. Karimi1, J. J. Baschuk, X. Li. Performance analysis and optimization of PEM fuel cell stacks using flow network approach, Journal of Power Sources, 2005, 147: 162-177.

[3] M. A. Danzer, J. Wilhelm, H. Aschemann, E. P. Hofer. Model-based control of cathode pressure and oxygen excess ratio of a PEM fuel cell system, Journal of Power Sources, 2008, 176(2): 515-522.

[4] M. Y. El-Sharkh, A. Rahman, M. S. Alam. Neural networks-based control of active and reactive power of a stand-alone PEM fuel cell power plant, Journal of Power Sources, 2004, 135: 88-94.

[5] R. P. O’hayre, S. W. Cha, W. Colella, F. B. Prinz. Fuel Cell Fundamentals[M]. John Wiley \& Sons, Ltd., 2006.

[6] J. Larminie, A. Dicks. Fuel Cell Systems Explained[M]. John Wiley and Sons, 2000.

[7] BCS Technology, Inc. 500W PEM Fuel Cell Operation Manual[M]. Bryan, Texas, 2001.

[8] Y. D. Zhan, J. G. Zhu, Y. G. Guo, J. X. Jin. Control of proton exchange membrane fuel cell based on fuzzy logic, Proceedings of $26^{\text {th }}$ Chinese Control Conference[C], Zhangjiajie, Hunan, China, 2007: 2015-2019.

[9] F. Barbir. FEM Fuel Cell: Theory and Practice. New York: Elsevier Academic Press, 2005. 